\title{
Analyzing IT Function Using COBIT 4.1 - A Case Study of Malaysian Private University
}

\author{
A. Abdul Latif and N. Hanifi
}

\begin{abstract}
This paper presents a study on an IT function of a private university in Malaysia and aims to assess the IT operations using an IT Governance framework which is COBIT 4.1. The goal of the study is to assess the 'as-is' situation of the IT function and using the result obtained to provide recommendation to the IT function. Selected employees from each department were interviewed and analysis of the data obtained from the interviews of the entire four units of the IT function was carried out. As a result, the use of possible IT governance is presented based on recommendation from the analysis conducted.
\end{abstract}

Index Terms-Governance, campus setting, IT function, COBIT 4.1.

\section{INTRODUCTION}

Every university engages in the use of information technology (IT). The role and impacts of IT on organizations have significantly changed since 1970s. IT has evolved from its traditional "back office" role toward a "strategic" role being able to support current business strategies and also to shape new business strategies. Nowadays, most of the management agrees on necessity of considering IT as an "organizational strategic player". As organization's strategy changes over time, IT has to change too.

Recently, increasing attention has given by business management to the topic of IT management, and to the emerging concept of IT governance. Many articles in the IT literature discuss and theorize the concept of IT governance, using different lens of analysis such as business and IT alignment, relationship between Chief Executive Officer and Chief Information Officer, IT management and IT use, IT function, and the role of IT. IT governance is one of important part in any business organization thus university campus setting. As like the term itself, IT governance is used to govern and handle IT related.

IT governance refers to the patterns of authority for key IT activities in business firms, including IT infrastructure, IT use, and project management [1] IT governance determines who makes the IT decisions and assigns accountability for the outcomes [2]; effective governance aligns IT investments with overall business priorities. Hence, IT governance is an important determinant of the IT goals and subsequent performance of the IT function. IT Governance also

Manuscript received March 6, 2013; revised May 16, 2013. This work was supported in part by the Ministry of Higher Education of Malaysia under Fundamental Research Grant Scheme.

A. Abdul Latif and N. Hanifi are with the Department of Information Systems, Universiti Tenaga Nasional, Malaysia (e-mail: aliza@uniten.edu.my, izzati@uniten.edu.my). describes who makes the decisions; who provides input and analyzes the issues; who sets priorities; and who settles disputes when there is no clear consensus. Good governance processes are actively designed and well-understood by participants and foster timely decisions that are communicated effectively. It is concerned with the entire enterprise IT function, not just the central IT organization.

In this research, the focus is on campus setting, where the IT function of a private university had been chosen as a scope for this research. As known, university have a lot of IT processes and resources, hence it need 'something' to govern and handle all those processes and resources so that the productivity and quality will always be the best and maintained for the users in the university campus. Besides that, all the IT services also can be delivered more reliable and more efficient. Due to a lot of function and services, it needs a good framework to govern all those IT processes and resources so that it can serve good services to the IT user. It also helps to avoid unwanted problem that can affects the campus setting process.

Thus, this paper aims to investigate the governance structure of the IT function by defining its structures, processes and mechanisms. All of these will be used to define decision making rights and responsibility about main IT issues, control and monitoring mechanism of the effectiveness of such decisions. COBIT 4.1 was used as a guideline to assess all the processes within the IT function, and for identifying a structure for a governance framework for the campus setting, an investigation was done on the IT units in the selected IT function.

\section{RESEARCH BACKGROUND AND METHODOLOGY}

The methodology for this research was using interviews, which was conducted on 23rd and 24th of March 2011. Interviews were conducted to gather information relevant to the research, and the respondents were all in manager level. The interviews approaches were divided into two, which were normal interview to assess the company structure, based on COBIT 4.1. Data was also collected from secondary method, through documentation analysis obtained from the company intranet or provided by the selected departments.

The units involved in these interviews were the Administration unit in Information Technology and Multimedia Services (ITMS), Network and Server unit that handle all the network, security and server related matters, Multimedia and Printing unit that handle all matters related to graphics, multimedia, and printing. Application Development unit manage everything related to system and application, including database [3]. 
The respondents of of the interview were all managers from all the units involved. They were given a set of similar interview questions, which varied from questions about their working experience, qualification, unit objectives, and their individual and unit roles and responsibilities.

The scope of this paper is focused on the structure of the IT function, which will be supported by the data obtained from the normal interview session. The objective of this interview is to know about their organizational structure, their job description and responsibilities, and the information about their department respectively. This information will be utilized in determining the optimal governance structure for the IT function, which includes the roles and responsibilities of each department and its staff.

The interview was held in different sessions to accommodate different department staffs. A set of similar questions as in Table I below was distributed to respondents, which was tailored to identify the roles and responsibilities of each unit within the IT function. Respondents were asked on their position, experiences, unit objectives, competencies and flow of information involved in their unit.

TABLE I: LIST OF INTERVIEW QUESTIONS

\begin{tabular}{|c|c|}
\hline No. & Interview Questions \\
\hline 1 & Which best describes your current position? \\
\hline 2 & $\begin{array}{l}\text { How long have you been working in: ( Please specify) } \\
\text { UNITEN? } \\
\text { Total working experience? }\end{array}$ \\
\hline 3 & $\begin{array}{l}\text { Do you have supportive, effective and efficient management in your } \\
\text { department? }\end{array}$ \\
\hline 4 & $\begin{array}{l}\text { Describe the work environment or culture and its management style } \\
\text { in which you have experienced the most success. }\end{array}$ \\
\hline 5 & What are the unit goal/objectives? Kindly describes. \\
\hline 6 & What best describes your department's IT goal? \\
\hline 7 & $\begin{array}{l}\text { In the task given, do you have a timeline (deliverable/response time) } \\
\text { to finish your task? }\end{array}$ \\
\hline 8 & $\begin{array}{l}\text { What factors are important within an organization and must be } \\
\text { present for you to work most effectively }\end{array}$ \\
\hline 9 & $\begin{array}{l}\text { Record individuals outside of the department who formally or } \\
\text { informally provide IT services. }\end{array}$ \\
\hline 10 & $\begin{array}{l}\text { List your IT competencies skills-what are areas of strength, either in } \\
\text { technical skill or in terms of hardware or software infrastructure that } \\
\text { will contribute most to competitive advantage for your department } \\
\text { and organization }\end{array}$ \\
\hline 11 & $\begin{array}{l}\text { List the ITMS strategic objectives ( Example: To maintain IT } \\
\text { support environment that is stable and reliable) }\end{array}$ \\
\hline 12 & List your main job description \\
\hline 13 & List your ad-hoc job description \\
\hline
\end{tabular}

\section{RESULTS AND DISCUSSION}

\section{Analysis of Units in selected IT function:}

Data obtained from the interview was used to identify the unit goals, timeline for each IT services delivery, the IT competencies or skills needed by the staffs, the ITMS strategic objective and the job description of each staff. All interview data from all the four units in ITMS were analyzed in determining whether it has a proper IT function.

\section{A. Administration Unit}

This unit's objective is to provide IT facilities and infrastructure to all business units in the university, focusing on providing business efficiency using state-of-the-art IT and communications equipment. All business unit need to send their IT requests, and they will be analyzed by the unit. The analysis of the request will determine the priorities of which business unit request to be catered first. All of the services delivered by this unit must comply with statutory requirement as well as the university ICT policy.

This unit also is the intermediary among all the business units in getting their IT services. It will liaise with other business units in the university, which include the faculties, procurement, finance and vendors who supply IT facilities. It main tasks is to ensure that there is no conflict of tasks among all the other units in the IT function. It will handle all the procurement process for IT facilities for the university, including pricing, ordering and procuring the items.

\section{B. Network and Server Unit}

According to a research by Standish Group in 2006 [4], 2 out of 10 enterprises IT projects are outright failures. The most common problem with any organizations management is the IT investment as it is the largest portion of an organization budget. IT investments are about enabling business change and can bring enormous returns if managed properly. By understanding the most of the budget allocation is for IT investment, the objective of this unit is to manage and control the use of computing facilities in the university in the safest, most reliable and economic manner. It aim is to provide reliable IT infrastructure and services at the lowest possible cost. Yet, without effective governance and good management, there is an equally significant risk to destroy value.

There is no RACI chart applied in this unit as it is not provided with a formal job assignment. In case of any incident, this unit will review the case and forward it to the technician on duty. If the case is critical or the technician assigned could not solve the case, it will escalate to the second level in the unit, which is the network executive. All incidents related to network or server will be forwarded through helpdesk unit, and the IT user will be informed of the case status.

\section{Multimedia and Printing Unit}

This unit also shares the same objective as network and server unit, which is to provide reliable IT infrastructure and services at the lowest possible cost. It mainly coordinates and operates multimedia and printing equipment and facilities. In order to control the cost of these equipments from escalating, the major task of this unit is to do preventive maintenance for all the equipments. This is to ensure that no ad-hoc purchases are made if any of the equipments is damaged.

The unit does not have specific operating policies of managing a problem. The only channel for the IT user to request for services is through phone calls and walk-in manner. This results in the user wanting the problems to be solved immediately without considering the nature of problems that they face.

As the unit does not have a formal RACI chart, the problems raised by users will be passed around until someone 
from the unit is available and able to solve the problems. It takes up to several days until a problem is closed, and the service resume.

\section{Application Development Unit}

The objective of this unit is to deliver new applications according to the scope and requirement and also to manage already deployed applications as well as solve or troubleshoot systems' problems efficiently.

This unit also manages two other sub-units that are database and helpdesk. All applications that are going to be developed will get support from database unit. As for helpdesk unit, they will be the medium for user to inform about their IT related problem.

\section{RECOMMENDATION}

The entire four units in the IT function have specific roles to play in delivering IT services to the end users of the university. This ranges from developing application for the usage of certain business units to printing tasks. Although, they have specific tasks to be done, it is clear from the description of each unit above that they do not have a proper roles and responsibilities for each unit and its staff.

Based on the studies conducted on the IT function, the only reporting structure that it uses is the distribution of IT services tasks to the four units as described above. These four units are responsible for the IT tasks given to them, but they do not have a clear reporting structure within the unit itself.

For example, in network and server unit, they do not have a formal schedule or chart for any task given. In case of any incident, staffs who receive the incidents will have to review the case although they may not have the skills or expertise to solve it. In some cases, they will escalate or forward the incidents to staffs in a level higher, which is the network executive. They do not have proper escalation procedures in case a problem could not be solved, which will cause delay or problem for the end user to do their routine IT works.

According to Weill and Ross [2], IT governance determines who makes the IT decisions and assigns accountability for the outcomes of the IT function for any organization. An IT governance framework is beneficial for an organization well-being as it help to measure how an IT department is functioning overall, what kind of metrics the management will use in measuring its performance and what is he return from the IT investment to the organization.

As specified in COBIT 4.1 [5], there are five areas of focus for IT governance implementation for an organization; namely Strategic alignment, Value Delivery, Resource Management, Risk Management and Performance Measurement.

Based on the interviews conducted for the campus-setting environment, they are applying at least two from the five areas of focus. Firstly, is the Resource Management, which applied to insure that the correct resources are deployed to perform the needed assignments. The IT function has identified four units to perform all the IT services that need to be delivered to users. However, they still lack in proper resource management by not having a proper task assignments for each unit staff. A RACI chart should be introduced to identify who is responsible for a particular task, who need to be accountable for the task, who need to be consulted if an incident happen and who must be informed about any particular task related to delivery of IT services. Secondly, they are implementing Performance Measurement, where they are putting structure around measuring business and IT performance. IT services delivered to the end users need to be measured using SLA (Service Level Agreement) or other metrics that are gathered and reviewed internally to IT, with the business or both. In current practices in the IT function, there is no SLA used for any IT services delivered to the end users. There are no means for users to know when they will be able to use the IT services once they report for any incidents or problems. The IT function should introduce SLA for all IT services that they deliver to the users to guarantee performance of specific services by all the units in support of the university business requirements.

\section{CONCLUSION}

This paper had discussed the current implementation of IT function in UNITEN campus. The results from the interviews conducted had showed that UNITEN already fulfill some part of IT governance by implementing a few areas of focus, namely Resource Management and Performance Measurement. This shows that IT function of UNITEN can be considered as 'moving positively' in implementing a full IT governance framework. However, for the IT function to apply a holistic IT governance framework, it is recommended that it implements all the five areas of focus as outlined in COBIT 4.1.

\section{REFERENCES}

[1] V. Sambamurthy and R. Zmud, "Arrangements for IT governance: A theory of multiple contingencies," MIS Quarterly, vol. 23, pp. 261-290, 1999.

[2] P. Weill and J. W. Ross, "A matrixed approach to designing IT governance," MIT Sloan Management Review, vol. 46, no. 2, pp. 26-34, 2005 .

[3] A. Abdul Latif and N. Hanifi, "Establishing IT governance using $\mathrm{CMMi}$ - A case study of Malaysian private university," International Journal of Future Computer and Communication, vol. 1, no. 3, pp. 221-224, 2012

[4] ITGI (IT Governance Institute), Governance of the Extended Enterprise: Bridging Business and IT Strategies, $1^{\text {st }}$ ed., Wiley, 2005, pp. 176.

[5] ISACA. (2007). COBIT 4.1. [Online]. Available: http://www.isaca.org.

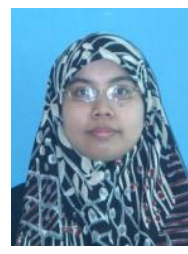

A. Abdul Latif was born in Malaysia on the $1^{\text {st }}$ September, 1980. She received her Bachelor in Information Technology (Hons.) in 2002 from Universiti Tenaga Nasional, Malaysia. She pursued her postgraduate education in University of Sussex, United Kingdom and received her MSc. in Information Technology for E-Commerce in 2005.

She began her career as a System Analyst in Tenaga Nasional Berhad in 2002, and continued her academic career as Lecturer in College of Information Technology, Universiti Tenaga Nasional since 2008. She is interested in research areas of IT Governance, Information Systems Management and Flood Management.

Ms. Abdul Latif is a member of Information Systems Audit and Control Association (ISACA) since 2010. She also is certified in ITIL v3 and COBIT 4.1. 